\title{
Cyclic variations in glycoprotein synthesis in the columnar cells of the human cervix*
}

\author{
H. J. M. Roelofs, R. J. van Kooij* $\dagger$ and M. F. Kramer $\dagger$ \\ Department of Obstetrics and Gynaecology, University Hospital, Utrecht, and $\uparrow$ Department of Histology \\ and Cell Biology, Medical School, State University of Utrecht, The Netherlands
}

\begin{abstract}
Summary. The rate of glycoprotein synthesis by the columnar cells of the human endocervix was measured during one cycle in 12 women by autoradiography. An increase in the rate of synthesis was associated with an increase in the plasma oestradiol concentration. A change in progesterone concentration in the blood did not seem to influence cervical glycoprotein synthesis. The ratio between the different cell types in the epithelium, basal cells, ciliated cells and mucus cells did not show cyclic variation in the cycles studied.
\end{abstract}

\section{Introduction}

One of the main components of cervical mucus, a mucous glycoprotein, is thought to be secreted by the columnar epithelial cells lining the cervical canal and its diverging crypts (Elstein, 1976). Indeed these cells show a well developed Golgi complex and many mucous granules indicative of a secretory function (Jordan \& Allen, 1977). However, a large contribution of endometrial secretions to the cervical mucus cannot be denied and these secretions could explain the cyclic variation in the amount and viscosity of the mucus, especially the peak amount of mucus in the ovulatory phase (Gordon, 1975). Major changes in the sugar composition of the cervical glycoprotein of 10 women during the cycle have been excluded (van Kooij, Roelofs, Kathmann \& Kramer, 1980).

In this study we have investigated the rate of glycoprotein synthesis in the cervical columnar epithelial cells during the cycle. We also studied the number of ciliated cells and the number and position of the so-called basal cells or reserve cells in a series of biopsies, to determine whether the ratio between the various cell types changes during the cycle.

\section{Materials and Methods}

\section{Patients}

Biopsies from endocervical tissue were taken from 12 healthy women attending the Fertility Unit of the Department of Obstetrics and Gynaecology of the University Hospital in Utrecht. All patients volunteered for the project. They were examined for primary fertility problems but, with the methods available, no reasons were found to explain their infertility. The criteria for selection were: (a) normal menstrual cycle length, (b) biphasic basal body temperature curve, (c) normal visco-elastic properties of the cervical mucus, (d) normal sperm penetrability in the cervical mucus, tested by Simms-Hühner tests and in-vitro penetration tests, (e) no abnormalities in the genitalia as

\footnotetext{
* Reprint requests to R. J. van Kooij, Laboratory for Experimental Endocrinology, Department of Gynaecology, University Clinic, 46 Schanzenstrasse, CH-4031 Basel, Switzerland.
} 
examined by bimanual palpation and hysterosalpingography, (f) the presence of only class I and II cells in the cervical smears according to Papanicolaou and $(\mathrm{g})$ no abnormalities in the semen of their partners.

Biopsies

The biopsies were taken with a Hajek biopsy forceps, which are normally used as bone forceps during sphenoid-surgery (Text-fig. 1). The size and form of these biopsy forceps make it possible to take samples from the endocervical tissues in the middle part of the cervical canal without traumatic dilatation and loss of blood. The volume of the biopsy is about $0.5-1.0 \mathrm{~mm}^{3}$, and its structure was not affected by the pressure exerted by the forceps.

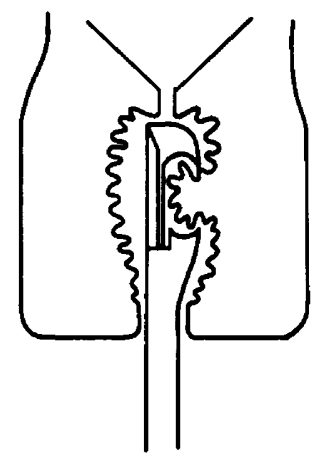

Text-fig. 1. Diagram of Hajek's forceps taking a $0 \cdot 5-1 \cdot 0 \mathrm{~mm}^{3}$ biopsy of cervical mucosa, crypts and lamina propria from the middle part of the cervical canal.

During the cycle 4-6 biopsies were taken. The interval between two biopsies was at least 1 day, but not more than 4 days. Practical reasons limited the number of biopsies that could be taken. Each biopsy in a series was taken from different places by rotating the forceps clockwise. The procedure was painless and well accepted by the patients, and did not prevent fertilization in at least 7 of the 12 women.

At the time of the biopsies the following measurements were taken : oestradiol and progesterone concentrations in the blood plasma (by routine radioimmunoassay), the amount of cervical mucus and changes in the appearance of the cervical ostium. The basal body temperature curve was noted during the whole cycle. It was possible to estimate the time of ovulation with the help of the abovementioned criteria with an uncertainty of 1 day.

\section{Incubation}

The biopsies were transported in Krebs-Henseleit buffer, $\mathrm{pH} 7.6$ at $0^{\circ} \mathrm{C}$ (van Venrooy, Poort, Kramer \& Jansen, 1972). Within 20 min the biopsies were transferred to $2 \mathrm{ml}$ of the incubation medium, which consisted of the same bicarbonate buffered medium, plus $0.1 \mathrm{~mm}$-uridine and glucose at $6.4 \mathrm{~mm}$. After incubation for $10 \mathrm{~min}$ at $37^{\circ} \mathrm{C} \mathrm{D}-\left[1 .{ }^{3} \mathrm{H}\right]$ galactose (sp. act. 9.7-22.0 Ci/ mmol; Radiochemical Centre, Amersham, U.K.) was added to a final concentration of $50 \mu \mathrm{Ci} / \mathrm{ml}$ buffer. After $10 \mathrm{~min}$ the incorporation was stopped by transferring the biopsy twice into new medium with an excess of unlabelled galactose. The tissue was then fixed in $4 \%$ buffered formalin.

The amount of radioactive galactose incorporated by the cells into glycoprotein during the incubation was a measure of the glycoprotein synthesis per cell. In preliminary experiments with endocervical tissue from surgically removed uteri we found that $\left[{ }^{3} \mathrm{H}\right]$ galactose did not metabolize during incubation for $30 \mathrm{~min}$ apart from its incorporation as galactose into high molecular weight 
material. When run through density gradients of $\mathrm{CsCl}$, the incorporated galactose accumulated between densities 1.45 and $1.50 \mathrm{~g} / \mathrm{ml}$. This is the density at which the cervical mucous glycoprotein concentrates (van Kooij et al., 1980). In one series (Patient 12) the biopsies were incubated in medium containing $100 \mu \mathrm{Ci} \mathrm{L}-\left[{ }^{3} \mathrm{H}\right]$ serine (sp. act. $19 \mathrm{Ci} / \mathrm{mmol}$ : Radiochemical Centre)/ml to estimate the rate of incorporation of an amino acid that is a major component $(12 \%)$ of the protein backbone of the cervical glycoprotein (unpublished).

\section{Autoradiography and quantification of radioactivity}

After fixation, $5 \mu \mathrm{m}$ methacrylate sections were made and covered by Kodak AR 10 stripping film. Exposure time was 5 days. The incorporated radioactivity was measured by counting the number of silver grains in the developed emulsion lying over areas of columnar cells in stained sections. The amount of $\left[{ }^{3} \mathrm{H}\right]$ galactose incorporated during incubation depends on the contact of the medium with the columnar cells. In the deep crypts the contact was less direct, due to the mucus that remained in the crypts. We therefore restricted the counting to the superficial layer of columnar cells.

The rate of $\left[{ }^{3} \mathrm{H}\right]$ galactose incorporation per cell was estimated by dividing the number of silver grains counted over a certain area of epithelium, by that area measured by planimetry in micrographs of the fields. This quotient is called Ratio I. Another estimation was obtained by dividing the grain counts by the number of nuclei in the area. Since this quotient showed the same variation as Ratio I, it is not used in this study. All counts and measurements were repeated twice. A minimum of three areas in one section was examined for each biopsy sample. The mean of the ratios of these areas was used as an index of incorporation per cell in a biopsy sample. In some biopsy samples, however, Ratio I was determined in 3 or more sections to get an estimate of the error of the determination per section.

Sections of the biopsied tissues were stained with haematoxylin and eosin or with PAS-iron haematoxylin for identification of secretory cells, basal cells and ciliated cells. In each sample 2501100 cells were counted. For 2 of the 12 women the relative percentages of these cell types were followed during the cycle.

\section{Results}

The numbers of silver grains per unit area of cytoplasm of cervical columnar cells (Ratio I) varied between biopsy samples from each woman (days of the cycle) and between women. The highest values in each of the 11 women in which galactose incorporation was measured varied between 0.41 and 1.87 , the lowest values between 0.05 and 0.58 . When measured in several sections per biopsy sample, the standard error for Ratio I varied between 5 and $72 \%$ (mean of 23 errors was $27.6 \pm 3.9 \%$ ). The standard error was not related to the amount of radioactivity incorporated (Ratio I), the number of sections (3-10) per biopsy sample, or the day of the cycle.

Plasma oestradiol levels varied between days of the cycle of each woman and between women. The oestradiol value in Patient 6 showed a very high peak $(485 \mathrm{pg} / \mathrm{ml})$, which was probably caused by a persistent ovarian cyst. The oestradiol values were in agreement with the known existence of a peak level shortly before and a second peak some days after ovulation. The plasma progesterone level started to rise at about ovulation, and did not decrease before Day 7 after ovulation.

The association between the changes in galactose incorporation and hormone levels was considered. The changes in the incorporation of galactose and plasma oestradiol concentrations coincided in $60 \%$ of the intervals (Table 1). In 17 intervals the galactose incorporation increased, in 3 it had a constant level and in 17 it showed a decreasing trend. Variations in Ratio I of 0.2 per day and in oestradiol levels of $4 \mathrm{pg} / \mathrm{ml}$ per day were considered as constant. The observed coincidence of $60 \%$ is significantly higher $\left(\chi^{2}\right.$ test : $P=0.05$ ) than the expected coincidence of $43 \%$. A possible 
Table 1. Coincidence of changes in $\left[{ }^{3} \mathrm{H}\right]$ galactose incorporation and serum oestradiol level during the menstrual cycle

\begin{tabular}{|c|c|c|c|c|}
\hline \multirow[b]{2}{*}{ Time of interval } & \multirow[b]{2}{*}{ No. } & \multicolumn{3}{|c|}{ Changes of Ratio I and oestradiol level* } \\
\hline & & Parallel & Non-parallel & Crossed \\
\hline \multicolumn{5}{|l|}{ Total } \\
\hline Observed & 37 & $22(60 \%)$ & 4 & 11 \\
\hline Expected $\dagger$ & & $15.9(43 \%)$ & $5 \cdot 5$ & $15 \cdot 6$ \\
\hline \multicolumn{5}{|l|}{ Observed } \\
\hline $\begin{array}{l}\text { Periovulatory } \\
\quad \text { (Day }-3 \text { to Day }+1)\end{array}$ & 17 & $(47 \%)$ & 2 & 7 \\
\hline Before Day -3 & 5 & $(80 \%)$ & 0 & 1 \\
\hline After Day +1 & 15 & $(67 \%)$ & 2 & 3 \\
\hline Before Day -3 and after Day +1 & 20 & $(70 \%)$ & 2 & 4 \\
\hline
\end{tabular}

* Changes in Ratio I and oestradiol level were registered as parallel, when both showed an increase, a decrease, or a constancy, as non-parallel, when one showed an increase or a decrease, and the other was constant, and as crossed when one showed an increase and the other a decrease.

† These values were calculated on the assumption that changes in Ratio I were at random, independent of oestradiol level, and the incidence of parallel, non-parallel and crossed changes is calculated from a binomial distribution.

association between the oestradiol level and Ratio I became more pronounced when only intervals before Day -3 and after Day +1 were considered, i.e. those outside the periovulatory days when oestradiol concentrations change rapidly. A significant linear correlation did not exist between the values of Ratio I and the plasma oestradiol level when all values were considered, but when only values before Day -3 and after Day +1 were observed, the correlation was significant at the $95 \%$ level (Mann-Whitney $U$ test), suggesting a relation between Ratio I and the level of oestradiol in plasma. The results of all measurements during a cycle of Patient 7 are illustrated in Text-fig. 2, and the galactose incorporation data for all 12 patients are in Text-fig. 3(a). When biopsies were taken during the days before ovulation, the incorporation of galactose showed a preovulatory peak (Textfig. 3b), but there was also a peak during the days after ovulation.

The rates of $\left[{ }^{3} \mathrm{H}\right]$ serine incorporation in the series of biopsies from Patient $12 \mathrm{fit}$ a model with a pre- and a postovulatory peak in glycoprotein synthesis. [ $\left.{ }^{3} \mathrm{H}\right]$ Serine incorporation had its lowest value at Day 4 after ovulation (Text-fig. 3).

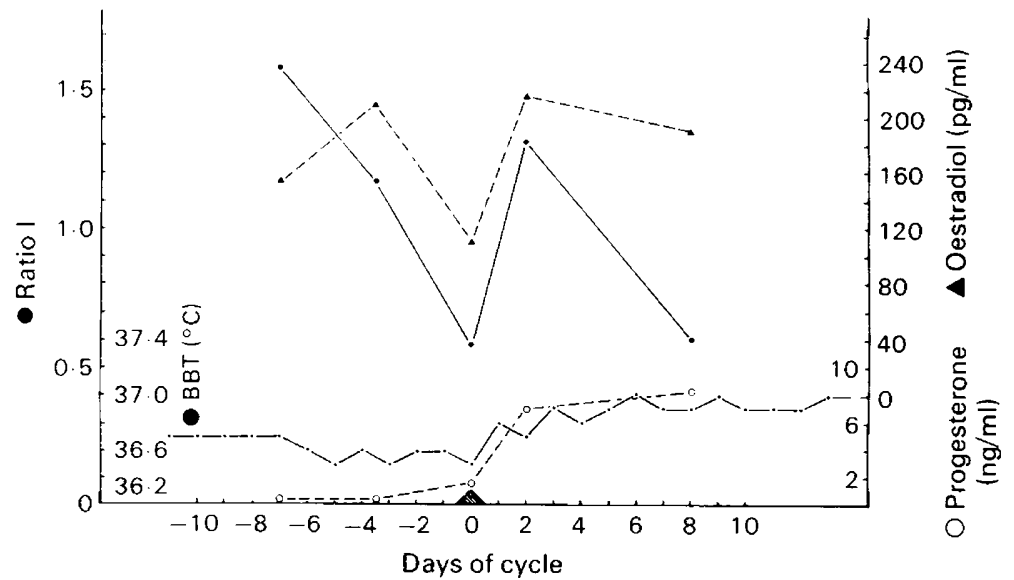

Text-fig. 2. Incorporation of $\left[{ }^{3} \mathrm{H}\right]$ galactose (Ratio I) and plasma hormone concentrations during the cycle of Patient 7. The presumed day of ovulation is Day 0. 


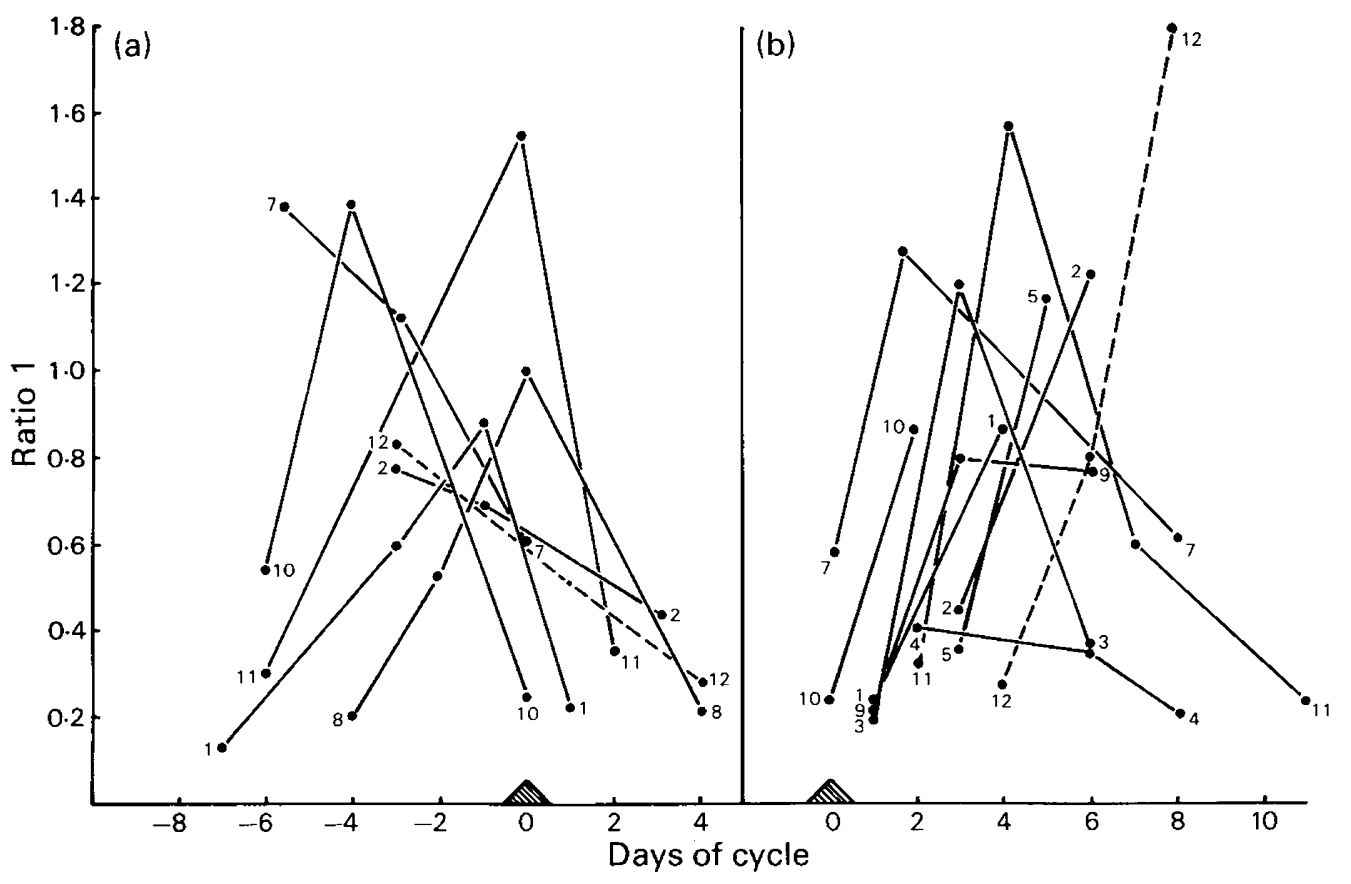

Text-fig. 3. Peaks of incorporation (Ratio I) in all patients during the cycle. The broken line represents $\left[{ }^{3} \mathrm{H}\right]$ serine incorporation (Patient 12 ). $\left[{ }^{3} \mathrm{H}\right]$ Galactose is used for the incubation of all other biopsies. The day of ovulation is Day 0 . (a) The peak of incorporation before or at ovulation and (b) the peak after ovulation showing constancy in 2 cycles, perhaps because no biopsy was taken on the day of the presumed peak.

The percentage of ciliated cells per biopsy sample ranged from $1 \cdot 1$ to $8.0 \%$ (means of all samples: $3.0 \pm 1.7 \%$ ). No cyclic pattern could be discerned in the 2 women in which the cell distribution was followed during their cycle (Table 2).

Basal cells, arranged in rows under the columnar cells were present in all biopsies. There was a significant difference ( $t$ test, $P<0.02$ ) in numbers of basal cells in the crypt areas and the

Table 2. Ratio of epithelial cell types in cervical biopsies during the cycle in two women

\begin{tabular}{|c|c|c|c|c|c|c|}
\hline \multirow[b]{3}{*}{ Day of cycle } & & & \multicolumn{4}{|c|}{$\%$ basal cells } \\
\hline & \multicolumn{2}{|c|}{$\%$ ciliated cells } & \multicolumn{2}{|c|}{ Superficial } & \multicolumn{2}{|c|}{ Crypt } \\
\hline & Patient 1 & Patient 11 & Patient 1 & Patient 11 & Patient 1 & Patient 11 \\
\hline-7 & $2 \cdot 8$ & & & & 0 & \\
\hline-6 & & & 19 & & & \\
\hline-3 & 2.9 & $6 \cdot 0$ & & & & \\
\hline-1 & $3 \cdot 9$ & & 6 & & 0 & \\
\hline 0 & & $2 \cdot 0$ & & 37 & & 1 \\
\hline+1 & $2 \cdot 9$ & & 0 & & 0 & \\
\hline+2 & & $4 \cdot 6$ & & 38 & & 0 \\
\hline+4 & $1 \cdot 1$ & $8 \cdot 0$ & 5 & 37 & 0 & 0 \\
\hline+7 & & $7 \cdot 0$ & & 29 & & 25 \\
\hline+11 & & 5.9 & & 31 & & 0 \\
\hline Mean \pm s.d. & $2 \cdot 7 \pm 1 \cdot 0$ & $5 \cdot 5 \pm 2 \cdot 2$ & $6.0 \pm 8.0$ & $34.4 \pm 4 \cdot 4$ & 0 & $5 \cdot 2 \pm 11 \cdot 0$ \\
\hline
\end{tabular}


superficial areas. In many samples no basal cells were seen in the crypts, while the superficial areas contained high numbers of these cells. Again no cyclic fluctuations were apparent in their ratio to other cell types (Table 2).

\section{Discussion}

In a preliminary publication (van Kooij, Roelofs \& Kramer, 1979) we suggested a possible association between glycoprotein synthesis and oestradiol level. The presence of two peaks of galactose incorporation and the correlation between changes in plasma oestradiol level and galactose incorporation support an association of the hormone level and the synthetic activity of the columnar cells of the human cervix. The rather low correlation might be explained by (1) the rather high error in the value of Ratio I per biopsy $(5-72 \%)$ which might be related to the great variations in appearance of the epithelial cells (Bradburn \& Webb, 1951), (2) the sometimes long intervals between biopsy samples which might obscure peaks and (3) the probable existence of a lag phase between the oestradiol level and galactose incorporation. If such a lag phase does exist, increasing values of the one would be accompanied by already decreasing values of the other. This would explain the poor correlation in the periovulatory days, when the oestradiol levels are changing very rapidly. A lag phase between oestradiol addition and stimulated protein secretion has been described in a breast cancer cell line: maximal stimulation occurred after $48 \mathrm{~h}$ (Westley \& Rochefort, 1980).

No effect of progesterone on galactose incorporation has been found. First, the mean value of galactose incorporation by all 25 biopsy samples taken during the postovulatory rise in plasma progesterone level did not substantially differ from the mean of the 24 samples taken before the rise of progesterone $(0.69 \pm 0.48$ and $0.58 \pm 0.40$ respectively). Secondly, the correlation between changes in galactose incorporation and plasma oestradiol level did not differ before and after the rise of the progesterone level.

The galactose incorporation measurement is subject to 2 criticisms. (1) The number of silver grains per cell is not corrected for the presence of non-secretory, ciliated cells in the areas counted. If their number decreased with higher oestradiol levels, the relative number of secretory cells incorporating galactose, and hence the number of silver grains per area would increase. This would result in an increase of Ratio I even when the rate of glycoprotein synthesis is unaffected. However, Table 2 shows clearly that the number of ciliated cells is low and does not show a cyclic pattern.

(2) Increased circulating oestradiol might decrease the intracellular pool of galactose. This would result in a higher specific radioactivity of galactose in the cell during the incubation and hence in a higher rate of incorporation of $\left[{ }^{3} \mathrm{H}\right]$ galactose, even at an unchanged rate of glycoprotein synthesis. If, however, the rise in galactose incorporation reflects a rise in the rate of glycoprotein synthesis, the first peak of incorporation would be followed by the peak in glycoprotein secretion, and this would give rise to the large amount of this component present in the cervical canal at the time of ovulation (van Kooij et al., 1980). The high amount of glycoprotein in the cervical canal at mid-cycle might be due not only to stimulated synthesis and secretion but also to a reported growth of the cryptal area of the cervix caused by oestradiol (Bernstein, Glezerman, Zejdel \& Insler, 1977). In our series of biopsies we observed that the number of basal or reserve cells in the cryptal areas was extremely low (Table 2). Gould, Barter \& Papadimitriou (1979) showed that basal cells could be involved in the replacement of the lining cells. Crypt growth by differentiation of basal cells into columnar cells is therefore considered unlikely. Crypt growth and subsequent increased production of mucus might be the result of divisions of secretory cells during the increase of the oestrogen concentration. However, we propose that an hormonal-dependent glycoprotein production in the existing cells offers a better explanation for the peak amount of mucus during the periovulatory days, because it also accounts for the subsequent decrease in production. The postovulatory decrease in galactose incorporation was apparent in all the biopsy samples studied. 
The second peak of galactose incorporation, between Days 3 and 8 after ovulation is not related to a measured peak in glycoprotein secretion in these women. However, Wolf, Blasco, Khan \& Litt (1978) described a small second peak in mucus wet weight in 2 women examined daily. In the light of the trend to a higher glycoprotein concentration in the luteal phase (van Kooij et al., 1980) this phenomenon might represent a second peak of secretion, following the peak in synthesis we describe here. Sometimes a second episode of 'mucorrhoea' is observed (Hartman, 1962). An antisecretory effect of progesterone has been suggested by Schumacher (1977). When there is a second period of mucorrhoea the progesterone level might be too low to inhibit fluid secretion.

We thank Professor J. Kremer, head of the Fertility Department of the University Hospital of Utrecht, for his encouragement and advice; Dr M. V. A. M. Kroeks, gynaecologist at the Diakonessen Ziekenhuis at Utrecht, who did the preliminary work in obtaining biopsies and incubating them for his thesis (Utrecht, 1976); and Mr R. Dol, who did most of the incubations and prepared the autoradiographs.

\section{References}

Bernstein, D., Glezerman, M., Zejdel, L. \& Insler, V. (1977) Quantitative study of the number and size of cervical crypts. In The Uterine Cervix in Reproduction, pp. 14-21. Eds V. Insler \& G. Bettendorf. G. Thieme Verlag, Stuttgart.

Bradburn, G.B. \& Webb, C.F. (1951) Cyclic variations in the endocervix. Am. J. Obstet. Gynec. 62, 997-1008.

Elstein, M. (1976) The biochemistry of cervical mucus. In The Cervix, pp. 147-154. Eds J. A. Jordan \& A. Singer. Saunders, London.

Gordon, M. (1975) Cyclic changes in the fine structure of the epithelial cells of human endometrium. Int. Rev. Cytol. 42, 127-145.

Gould, P.R., Barter, R.A. \& Papadimitriou, J.M. (1979) An ultrastructural cytochemical and autoradiographic study of the mucous membrane of the human cervical canal with reference to subcolumnar basal cells. Am. J. Path. 95, 1-16.

Hartman, C.G. (1962) Cyclic changes in the endocervix of the monkey and the origin of the cervical mucus. Ann. N. Y. Acad. Sci. 97, 566-570.

Jordan, J.A. \& Allen, J.M. (1977) The ultrastructure of cervical epithelium. In The Uterine Certix in Reproduction, pp. 21-35. Eds V. Insler \& G. Bettendorf. G. Thieme Verlag, Stuttgart.

Schumacher, G.F.B. (1977) Cervical secretion-a prod- uct or a target organ for estrogens and gestagens. In The Uterine Cervix in Reproduction, pp. 101-108. Eds V. Insler \& G. Bettendorf. G. Thieme Verlag, Stuttgart.

van Kooij, R.J., Roelofs, H.J.M. \& Kramer, M.F. (1979)

Composition of human cervical mucus and synthetic activity of endocervical cells during the menstrual cycle. In Glycoconjugates, pp. 546-547. Eds R. Schauer, P. Boer, E. Buddecke, M. F. Kramer, J. F. G. Vliegenthart \& H. Wiegandt. G. Thieme Verlag, Stuttgart.

van Kooij, R.J., Roelofs, H.J.M., Kathmann, G.A.M. \& Kramer, M.F. (1980) Human cervical mucus and its mucous glycoprotein during the menstrual cycle. Fert. Steril. 34, 226-232.

van Venrooy, W.J., Poort, C., Kramer, M.F. \& Jansen, M.T. (1972) Relationship between extracellular aminoacids and protein synthesis in vitro in the rat pancreas. Eur. J. Biochem. 30, 427-433.

Westley, B. \& Rochefort, H. (1980) A secreted glycoprotein induced by oestrogen in human breast cancer cell lines. Cell 20, 353-362.

Wolf, D.P., Blasco, L., Khan, M.A. \& Litt, M. (1978) Human cervical mucus. IV. Viscoelasticity and sperm penetrability during the ovulatory menstrual cycle. Fert. Steril. 30, 163-169.

Received 7 December 1982 